\title{
Indicators of the Process of Transition to the Exercise of Family Caregivers of Elderly with Parkinson's Disease: A Qualitative Study
}

\section{Simony FL Nunesc*}

Federal University of Maranhão, Imperatriz, Maranhão 65900-000, Brazil

"Corresponding author: Simony FL Nunesc, Federal University of Maranhão, Imperatriz, Maranhão 65900-000, Brazil, Tel: +55 98 3272-7630; E-mail: sflnunes@hotmail.com

Received date: August 24, 2017; Accepted date: October 12, 2017; Published date: October 20, 2017

Copyright: (C) 2017 Nunesc SFL. This is an open-access article distributed under the terms of the Creative Commons Attribution License, which permits unrestricted use, distribution, and reproduction in any medium, provided the original author and source are credited

\begin{abstract}
The objective was to study the indicators of the process of transition of family caregivers and the influence of this in the care for elderly with Parkinson's disease in the family context. This study is exploratory, descriptive and qualitative conducted with 20 family caregivers of older adults with Parkinson's disease. The results revealed that, at the passage of exit from transition, family caregivers show integration of the routine of care in their personal life, acceptance of the health state of their relative through positive view of the disease, as well as they use strategies to acquire skills related to care for elderly with Parkinson's and they recognize in themselves the identity of family caregivers. Interventions are needed to identify the specific concerns of family members to strengthen and facilitate the process of transition to exercise the role of caregiver, in face of the various changes in routine that Parkinson's raises.
\end{abstract}

Keywords: Parkinson's disease; Family; Caregivers; Elderly; Nursing

\section{Introduction}

Parkinson's disease (PD) is a chronic and progressive neurodegenerative disease of universal distribution that affects all ethnic groups and socioeconomic classes [1]. It is considered a multisystem disorder difficult to define due to the presence of motor symptoms in initial stages, such as gait disturbance and postural instability that become progressively complicated by autonomic, cognitive and neuropsychiatric dysfunction. This disease represents a major clinical challenge because it is one of most common neurodegenerative diseases, mainly affecting the elderly population, a group whose size is increasing rapidly in the world, besides lacking therapeutic means to influence dopaminergic loss $[2,3]$.

Adapting to changes arising from the functional changes that PD causes demands new forms of organization from family caregivers, and requires the development of skills to deal with pressures, anxieties, difficulties and uncertainties in the daily care the person with PD [4]. Thus, nursing care for the elderly with PD in the family context depends on knowing the indicators of the process of transition of family caregivers and its influence on their performing tasks.

In this scenario, the disease causes changes in the routine and planning of activities of family members, as they take on the commitment and responsibility to provide health care, what demands medical, social and emotional skills [5].

Thinking about the reality of families, some authors argue that PD, as a complex chronic disease of high social and economic impact, ultimately affects not only the persons who have the disease $[6,7]$, but all those who live with them, since most of these patients are cared for at home by family caregivers. The caregiver is generally the closest family member, the one with whom the person with PD shares daily events and the small achievements in face of the problems incurred by the disease [8].
Effective interventions from nurses toward family members who are in transitional situations require a better understanding of the main needs of the disease's trajectory. Therefore, the Theory of Transitions developed by Meleis [9] was selected as the theoretical framework for the present study to provide a comprehensive view of transitions that can serve as useful guidance for designing early interventions for family caregivers of older adults with PD.

By defining transitions as "a transition from one stage of life, condition or state to another" and believing that nursing has the purpose to promote the success of these transitions, regardless of the people involved, life, health, circumstances or the context of care, and the theorist defined the response patterns to guide the nursing therapies in the process of transition [9-11].

Hence, in order to confirm that the transition is moving toward the end, and toward stability in the play of the new role, patterns help nurses to assess the situation referring to a positive outcome. This response pattern is divided into process indicators, viewed by feeling connected, interacting, having perspective and building trust and coping and outcome indicators expressed in mastery and fluid integration $[9,12]$.

Thinking about the indicators needed to signalize the exit from a process of acquiring a new role in the family, as the caregiver, the aim of the present study, in the light of the Theory of Transitions, was to identify the indicators of the process of transition of family caregivers and the influence of these in the care provided to the elderly with Parkinson's disease in the family context.

\section{Methods}

\section{Design}

A descriptive exploratory study with a qualitative approach was carried out using Theory of Transitions [13], as a theoretical 
Page 2 of 7

framework for understanding the meanings that reflect the experience in adapting to play the role of family caregivers.

\section{Setting and participants}

Study participants were 20 family caregivers of people with PD who live in Florianópolis, Santa Catarina, Brazil, selected from the register of the Parkinson Association of Santa Catarina (APASC). The selection criteria for the study were: be the caregiver of an elderly with $\mathrm{PD}$ registered in the APASC, be a blood family member or a close person of the elderly diagnosed with PD; be the primary caregiver responsible for partial or full day care of the elderly, for a minimum of six months in the home context and reside in Florianópolis. Exclusion criteria were: people aged less than 18 years and those who did not comply with the inclusion criteria.

\section{Instrument and data collection}

Data collection was conducted from March to August 2015 through qualitative interviews using a semi-structured script focusing on the objective of the study from the perspective of family caregivers of older adults with PD. The questions were inspired by literature on family care of people with $\mathrm{PD}$. Interviews were conducted until reaching saturation, which was confirmed when new thoughts on the subject were no longer displayed and the data become repetitive [14]. The interviews were recorded with multimedia equipment player and transcribed in full length to be used in the analysis.

\section{Data analysis}

Transcripts were processed with the help of ATLAS.ti version 7.2 a software for qualitative data analysis (Scientific software developed by $\mathrm{GmbH}$, Berlin, Germany). The coding team consisted of four members. Thematic analysis was then conducted with a smaller subset of the coding team (two members).

The transcripts were read several times to get a sense of all the material and the raw data were analyzed by labeling all relevant citations with codes (pre-analysis). Once encoded, data were grouped into potential conceptual issues (exploration of material) and then classified into core themes (treatment of results, inference and interpretation), according to content analysis [15].

\section{Ethical consideration}

Verbal and written information concerning the study aims, voluntary participation, and confidentiality were given to the participants in accordance with research ethics. The study was part of the project "The transition of the family member of elderly with Parkinson's disease to the role of caregiver" and was conducted in accordance with national and international standards of ethics in research involving human subjects for which received approval from the Ethics Committee of the Health Department of Santa Catarina (Opinion $\left.\mathrm{n}^{\circ} / 1.002 .947 / 2015\right)$. To ensure anonymity, participants were identified by the letter F, family, followed by the numbers corresponding to the interviews; thus, the first respondent received the identification "F1", and so on.

\section{Results}

\section{Description of the sample}

The study included 20 family members responsible for the care of elderly with PD that had their profile composed as follows: 16 were female and 4 male, aged between 37 and 85 years with a mean age of 61 years. Concerning the degree of relatedness with the elderly, there were 11 spouses, five daughters, one niece, one daughter-in-law, one sister and one mother. Regarding the level of education, most had not finished elementary school and only seven had higher education. As for religious affiliation, 15 participants reported to be Catholics, three were Kardecist spiritists, one was evangelical and only one reported not believing in God or any other idea of superior being.

Still with respect to the characteristics of family caregivers, it was found that 14 family caregivers were married, three were single, two, divorced and one, widow. Thirteen were retired, three had active employments, two were unemployed and two reported being housewives.

\section{Indicators of the process of transition of relatives of elderly with Parkinson's disease}

Several themes emerged about the meaning assigned to transition during interviews. Participants discussed the acceptance of the health state of their family member through a positive view of $\mathrm{PD}$, the integration of the routine of care in their personal life, strategies to acquire skills related to care for elderly with Parkinson's disease and they recognize in themselves the identity of family caregivers

These four themes allowed the identification of process indicators and of result present in the transition of the family member of elderly $\mathrm{PD}$ to the exercise of the role of caregiver. The "integration of routine care and acceptance of the health status" were allocated as process indicators for understanding aspects such as communication, personal perspective in the transition and the development of confidence. In turn, the themes "strategies used to acquire skills related to the care of elderly with PD" and "recognizing in oneself the identity of family caregiver" figure as a result indicators because they revealed as characteristics reliability, confidence and because they walk hand-inhand towards the sense of well-being. Figure 1 provides an overview of the topics to be discussed.

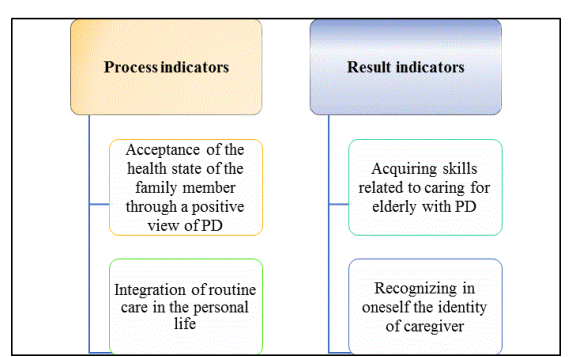

Figure 1: Schematic representation of the indicators of the transition of relatives of elderly with Parkinson's disease to exercise the role of caregiver. Florianópolis, Santa Catarina, Brazil, 2015. 


\section{Acceptance of the health state of the family member through a positive view of $P D$}

The family is shown within the transition process, when accepts the health status of the elderly with PD. Some participants in this study acknowledged that despite the changes brought with the disease, to live with the elderly affected by PD is part of the natural family living. The following lines explicit evidence of this analysis:

So, it is normal. Thank God I have nothing to complain about something that the disease has brought. F2

But these lives are like this, really. One day you're well and the other day you may get sick, especially those who are older, and I'm gonna tell you something, for someone who has this disease already for long, he is doing well. F18

During the transition process, the acceptance of the health state of the elderly with PD arises through conformism and feelings of hope for the perception of improvement, of signs or symptoms linked to the disease.

We accept this disease very well. Unfortunately, it is there. But as he is using now another medicine, he does not tremble so much. So, it is fine. Sometimes, here he walks very slowly, very short steps, and trembling a little, but on the street I've seen he does big steps. F7

What can we do? There is nothing to do. We have done this: our life continued as if nothing had happened, you know? I do not keep suffering because of this. You have to accept what comes. No use of getting revolted for a disease that is there and that has no cure. No use, it doesn't change anything at all. F9

Thank God, even with Parkinson's; she is lucid and also independent, what is important. F19

Another important factor for acceptance of the disease, constituting the aspects of interacting and having perspective, was to compare the disease to other more serious diseases. It was noticed that this creates a comfort to family and helps in the process of accepting the disease, as expressed below:

But, it is a disease that at the same time the person feels no pain, no need to take morphine, no, nothing like that. F11

All these years he has given us no trouble. If he keeps as it is, well, especially the issue of lucidity because my ex-husband has Alzheimer's, and that I think is worse, in all senses. F9

\section{Integration of routine care in the personal life.}

This theme highlights the importance of the family member to integrate actions related to care in their daily routine. The main activities performed by family caregivers of the study to aid the needs of elderly with PD were: follow-up in consultations, preparation of meals, help with daily activities and decision-making, administration of medications. Only one elderly was bedridden and needed help to all ADLs and for instrumental activities of daily living (IADL).

At this stage she is, I am the one who does everything. For example, house cleaning, food, separate the drugs for her to take, take her to places. Everything. F1

We have time for everything, because he does all the activities of APASC three times a week, he does exercise on Mondays, Wednesdays and Fridays. And as I am the one who take him there, I organize myself to leave him, and then I go to my water aerobics. I always finish five minutes before the schedule to allow time to get ready and to able to pick him up. In the days of group meetings, while he's there, I'm doing something else, then I pick him up. F6

I am very afraid when she goes out alone, especially to go to the support group, because there in front of the building there is a lot of traffic, we have had accidents with colleagues, elderly have been robbed, and as she is so fragile that I'm afraid that someone takes advantage of her weakness. F19

Another important item observed in the reports related to the integration of routine care in the daily personal life is that, if not well informed and monitored, it may cause impairment of communication among family members, generating burden for the caregiver by directing all issues of the family life to the disease:

It's funny because the person does not realize and when you see, you are all day long talking about disease, medication, you know? You sit down to have lunch and begin to talk about issues related to the disease: "Oh, she did not evacuate." "Oh, she did not take the medicine." "Oh, we have to go to the clinic take the medicine." "Other issues simply do not exist. F5"

One aspect related to the caregiver's development of strategies was to have labor activities as a distraction from the intense routine of care.

But the part that make food to sell is not because of the expenses, it's to distract myself a little, get away, for a moment, from this issue, to be here all the time taking care. When I'm cooking, I focus in other thing, you know? F8

Today I'm already doing my things again. And, there is also the part of administration of properties, there is always something to solve, so I can distract myself with other things. Because to be all the time around the sick person is impossible. F11

There are also cases in which relatives with direct kinship assume exclusively and spontaneously the function of caregiver in addition to other household functions, as evidence by the following statement:

When you're wife and find yourself in a situation like this, you have to take everything and do it, you have to be a housewife, mother, take care of the finances, be the office boy, or in my case office girl, the driver and do everything the person may need because you are responsible for caring of her. F7

\section{Acquiring skills related to the care for elderly with PD.}

The data analysis showed that the mastery of new care skills expresses the consolidation of the process of transition and indicates the direction of the final state.

Because I've read a book long ago, a book by "Jacks Lemon," with the title my dear father, talking about diseases, where the wife was a very thorough person with the old sick husband, and did everything for him. And the author said it was a mistake, because one has to be as independent as possible, then this wonderful book made me see that I cannot interpret my husband's illness as a "you cannot do it!" "You are no able to do it!' On the contrary, I have to encourage him to do the most he can do by himself. F7

However, the characteristics of the evolution of PD make a monitoring of the family member responsible for care needed so that the skills in care management be carried out properly, aiming at the best performance of the role of caregiver:

From the beginning, I always knew I was responsible for him and I always did everything, but I have doubts about the evolution of the 
disease, because in every disease we are afraid of evolution, any disease. Even when the chance is small, we always fear the evolution, how he will be in the future, if he will need a wheelchair and how it will be to look after him. Because one thing is to get old, and another thing is to have a disease that has no cure at this age. F10

The statements of the family members reveal the need to feel assisted by health professionals so that interventions drawn toward them may help them to carry out their activities properly. Some participants seemed insecure about their skills to meet the needs of the elderly within the new environment of care. Other participants defined themselves as more confident in performing care activities, especially those that developed this care over many years:

Another day he had a seizure and was stunned when he kneeled down. So, I think knowledge about emergencies is essential to help in a moment like this. Unfortunately, I do not have such knowledge, but it is essential for you to know how the person is and if it is ok. As I do not know much, the first thing I do and get him into the car and take him to the polyclinic, but it is necessary to have this initiative and attitude, at least this I have. F5

Over time, you develop skills to be caregiver, because we need the affection, commitment, care and knowledge. Because to take care of a person you have to know from the medication times to recognize how the blood pressure is. For example, these days she got dizzy and I had to notice this, in order to know where to take her, besides taking note of everything to inform the doctor. F14

\section{Recognizing in oneself the identity of the caregiver.}

A positive and healthy result from the experience of transition is to express attitudes that show the reformulation of identity, recognizing the self as part of the process.

The personal meaning given about what means to be a caregiver is one of the indicators that the nurse can use to assess if the process of transition is taking place satisfactorily. The analysis of the meanings to which family members perceive themselves within the care of the other shows how they see themselves within the process. To have attitude, dedication, initiative and availability were the main features raised by relatives as necessary for them to satisfactorily perform the role of caregiver, as shown below:

The person needs to have attitude. You have to be well connected with some things. F3

\section{I am more ready to listen and help. F5}

The caregiver must have dedication; you have to go after the things needed. F6

\section{You, as a caregiver, you need to have initiative. F2O}

Another form of recognition of identity as caregiver among study participants was observed in the need to take care of the self, in order to be well physically, to have the strength to care of the other:

It is clear that not only the sick person, but also the caregiver needs care. Otherwise, the caregiver can't stand it. He does not practice a therapy, a sport or weight-training, hydro, nothing, he does nothing. In a little while he will not take care of anyone. F1

The caregiver has to take care of himself; you have to take care of yourself. Because we grow tired in a way that if we do not pay attention, we get sick, just as the sick person you are taking care of, or worse. Look, it's not easy. If you do not pay attention, you get sick. F11
Study participants have the opportunity to be inserted in an association that offers a variety of physical activities for the person with PD and for the caregiver. As a way to take care of themselves, participants reported doing various activities such as walking, acupuncture, weight training, aerobics and others:

I take only medicines for cholesterol. But I always walk, I do exercises, regularly. I do all the activities of APASC because it is a conduct adopted by the association, to take care of people with Parkinson's and their caregivers as well. This should be the correct thing to do, that all people with the disease had their caregiver participating in the activities. F1

I'm now doing acupuncture; I'm really enjoying it, because acupuncture makes me feel good. It gives me lots of energy to endure the day. F9

I practice cooper, gymnastics, stretching, weight training. You have to do all of this, to always be able to help. F13

The adjustment of the focus of attention toward the family member responsible for elderly care was a topic raised by some participants of the study. The reports show the need to look at the caregiver from the very beginning, from the discovery of the disease, because this is also protagonist in this event, as the changes involve all family members, as highlighted by one participant:

The person who takes care must be taken seriously. This person needs care as well. F1

So I think that this aspect should be further explored, this about the caregiver, you know? While you do not know what's going on with the person, because it takes some time to settle what's really going on. It takes time to understand that the person is sick and all her function there. F8

\section{Discussion}

According to theorist, when nursing evaluates a situation of transition, it must understand the individual circumstances of each subject involved and the meaning that this attaches to the experience, [15] and the Theory of Transitions suggests using the response patterns to assess the setting of coping in the moment of change and adaptation in the acquisition of a new role.

In this sense, found in their literature review that many articles on the world scenario convey that caregivers and patients evaluate home care as positive, when considering the patient's proximity to the family, for being in their home context [16].

The statements of the present study revealed that for the family members, the most important are that the elderly with PD are aware and living with independence, as much as it is possible. In this sense, some authors say that, because it is a neurodegenerative disorder, the prognosis of PD indicates a progressive decline in cognitive and motor function, with risk factors for faster reduction of this function for people in advanced age at diagnosis, and $60 \%$ of patients who have the disease develop dementia within 12 years after diagnosis [3].

Nurses are responsible for providing information that can help family members who are caregivers to be prepared to accept of this role and the disease of their relative itself. Accordingly, a study on the effectiveness of a program of intervention for family caregivers indicated that they were more confident in dealing with situations related to the progression of the disease and in providing the care 
needed, as well as they perceived they were becoming more dynamic and wise in planning for the future when they received guidelines in the education program focused on acquiring skills to help family members to adapt to their new role [17].

The ability of have perspective involves finding justification for how or why they are in this situation. It involves understanding the new life, comparing it with the age, with normal patterns of perception. The condition of having perspective, in the case of the participants of this study, showed variation in that they came to an understanding and acceptance of how they were in their current situation [12].

In the study, the family members revealed that realizing the positive issues in $\mathrm{PD}$, taking into account that there are other more complex and serious diseases, lead them to accept the situation and accept living with the elderly with PD and, hence, moves them towards a healthy transition. However, research conducted in Australia that aimed to compare the needs for supportive care and the needs of caregivers of people with motor neuron disease (MND), multiple sclerosis, Huntington's disease (HD) and PD found that the multiple sclerosis group was less likely to have a caregiver and more likely to live alone and the HD and PD groups had the highest rates of anxiety due to the level of care required by the disease [18].

Study on the use of educational technologies of the family members in providing informal care to the person that depends on others at home revealed that membership in educational programs focusing on the changes resulting from the aging process and the worsening of the disease conditions improved knowledge, positively impacting the practice of home care [19].

Nurses and other health professionals should recognize that family participation during treatment and evolution of the PD of a patient is important for both the health professional and the patient. However, easy access to specialized services in PD is needed for ensuring the family binomial caregiver/elderly with PD the sense of security and confidence in being well taken care of $[20,21]$.

As evidenced in the results, it is clear that when family members feel able to keep track of decisions, scaling their time in the planning of care to other person and when they are well supported, they are more likely to adjust well to the performance of the role of caregiver. This result converges with the findings of a narrative review of home care on the world scenario, in which the analysis of the studies showed that taking care of a family member requires the establishment of a new routine and reset daily activity [16].

The statements identified concern for the elderly and care provided by the family member such as: adherence to implement the treatment plan; knowledge about the disease process and treatment plan; assistance in activities of daily living, whether basic or instrumental; providing emotional support to the elderly with $\mathrm{PD}$; monitoring of their capabilities in the provision of care; and confidence in the performance of tasks. All these can be considered process indicators for a healthy transition.

Process indicators are useful to identify whether clients are moving towards health or towards vulnerability, and to continuously evaluate the risk of unsatisfactory transition [12,13]. Associated with this thought, the study revealed that communication between the members of the family goes through several changes during the mild and moderate stages of PD, but remains as the cornerstone of harmonious family operation that allows solving problems and prevention of conflicts [22].
Consistent with other studies, it was found that the burden of taking care is strongly associated with motor impairment and with the severity of the disease [22]. This reinforces the importance of implementing early interventions to prevent or lessen the burnout of caregivers $[23,24]$.

The meaning of transition and the behaviors developed in response to the transition are revealed, clarified and recognized through interaction, creating a context in which self-care and care may occur in a dynamic and harmonious way [25]. Feeling connected; interested about making new contacts and maintaining the old relationships are effective in a process of transition.

Therefore, the nurse specialist in PD must have a detailed perception about the fact that a family-centered approach is absolutely crucial in order that all actors involved in the process may obtain the maximum benefit from in-depth knowledge [21]. Insight and understanding that living with PD patients can be a huge pressure on spouses and that the person with PD is invaluable must make nurses to combine advice, information and emotional support in their practice professional in order to help families to cope with the situation in the best possible way [21].

The results of a study in India found that spouses and children perceive care as a duty and therefore assume the function. However, this attitude may prevent them from admitting their real burden, even when they are experiencing stress and tension in exercising the role of caregivers [23].

In this study, the experiences of family members give evidence that, while there is a pattern indicating that those involved are experiencing an increase in their level of confidence, they develop strategies for care management and coping skills for problem solving, even when the circumstances are not favorable and the demand for care is in high. To theorist [13], when this occurs, it is a sign that they managed to reach a level of comfort, well-being.

Research in Canada with elderly spouses in moderate stage of PD found that nurses should address the basis of relationships and interactions, to identify the main intervention needs of couples and their preferences. This will result in a more harmonious functioning of the couple in terms of communication, problem solving and adjustment to roles, promoting a successful transition [22].

Since there are no specific markers to identify the onset of PD or progressive stages of the disease, the diagnosis and progression of the disease is based on clinical signs and symptoms [26], which make the family member to develop daily care skills.

The testimony reveals that the experience and gaining knowledge make the caregiver to interpret the disease with a new look with the passage of time living with the disease. Therefore, the family member is evaluated over time based on his ability to perceive, ability to adapt and to cope, essential conditions for providing care [24]. In addition, information should be provided to families regarding social services that may provide assistance at various stages of the disease [26].

According to some author, despite the difficulties that family members who are caregivers face, they attach importance to the challenges that arise over time and develop strategies in order to adapt effectively, demonstrating a positive sense of competence [27].

About this, some studies show that, while family members demonstrate mastery while dealing with the situation of taking care of a dependent person, the health team may facilitate or hinder their 
participation in the provision of activities of direct care and decisionmaking [25]. The theory defines this feature as mastery, a feeling of achieving a highly qualified role and the comfort with the behavior required by the new situation, represented by individuals starting to make their own decisions and taking control of the situation [13].

The study, using the Theory of Transitions with family members of elderly, reported that family members who had practice the care for longer had a greater ability to develop the activities [25], but they resisted the healthcare team's guidelines for knowing the best way to perform actions care.

Research carried out in Sweden in order to identify and describe the role of the nurse expert in PD in the support to patients and their spouses found that this professional should have deep knowledge of disease progression, of medical and surgical treatments available, as well as possible side effects, and mainly, should have enough knowledge to be able to give professional advice to family members when questions or complications arise in the disease or its treatment [21]. Another study showed that Parkinson's expert nurses need active listening skills and the ability to assist families in establishing goals related to health care and contingency plans, to facilitate the performance of role of caregivers by family members [26].

The statements of this study complement previous study findings, conducted with eight elderly with PD members of the Mutual Help Group (MHG) at a university in southern Brazil, which expressed that the PD has to be shared with the family, since feeling supported by the family facilitates coping with the disease, and the presence of family members is essential for emotional stability and increased self-esteem [20].

It was observed that, in addition to the activities offered by APASC, many family members take care of their health by practicing free activities such as walking and complementary treatment therapies. Similar results were found in Canadian study with spouses of elderly with PD, where couples, when they sense the need to stay healthy, they develop effective strategies to maintain their own physical, psychological and cognitive health [22].

Thus, listen to the questions and concerns of the family member and observe the responses of involvement in the process are a priority. Similar results to those found in the present study support the idea that family members who are caregivers of people with addictions need to be the subject of care and need to receive differentiated support, especially emotional support [19].

Other studies researching different populations have consistently shown that family members of people with PD, especially spouses, feel supported when the nurse dedicates ample time to sit with them and allow them to tell in their own words how they experience the situation $[21,22]$. By listening carefully to the patient and the spouse, the nurse is able to assess the family needs and the actions required to make daily life of PD more simple, and is also able to assess the needs and desires that must be met in the current situation, making that the individual concerns of each family member may be addressed [21].

The results of this study reveal that undergoing a transition to the new role of caregivers requires time, preparation and development of skills. It is suggested then that, at each stage of the transition, nurses have in the theory of transitions of Meleis, nursing therapies prepared to: work in partnership with the family of the elderly with PD; be aware of the burden that family members who are caregivers are experiencing and try to minimize them; ensure that everyone involved in the precession of PD be informed about the disease and about available resources; enable caregivers to control the events and decision making; teach them the importance of caring for themselves; and ensure that they are physically and emotionally assisted.

\section{Implications for practice}

The results of this research contribute to the reflection on that supporting the family in times of transition is an important function of nurses and of professionals who work with families in unexpected situations of chronic diseases, as it provides a broad understanding of the family experience.

Finally, we believe that nurses providing primary care and nursing educators can use these considerations based on theories to identify potential vulnerabilities in the family's adaptation to the unexpected event of a chronic disease. In addition, these results may provide justification for the development and planning of interventions to improve the quality of care for elderly with PD and their families.

\section{Limitations and Future Directions}

In this study, some limitations must be considered, such as the fact that all study participants be caregivers of elderly assisted by an association that has several activities and partnership with the academic community. Thus, the experiences described in the local health system cannot be generalized to other family members who have no support network in this configuration. These limitations serve to emphasize the importance of conducting further research including data collection with larger samples and for longer periods, to provide a better understanding of the factors influencing the responses of family members to the changes brought up by living with degenerative diseases.

\section{Conclusion}

The facilitation of successful transitions is within the purposes of the actions of nursing professionals, and the Theory of Transitions enables us to explain the aspects of transition from health to illness in the family context. Therefore, it is beneficial to understand the impact that the changes arising from the disease may cause in the lives of family members, to guide the nurse's practice towards encouraging family caregivers in the recognition of their contribution to successful transition.

The main contribution of this study is to identify the needs of relatives of elderly with PD in providing care in the home environment and identify indicators that refer to the achievement of a positive and healthy result of the exercise of the role of caregiver.

\section{References}

1. Benavides O, Alburquerque D, Chana-Cuevas P (2013) Evaluación de la sobrecarga en los cuidadores de los pacientes con enfermedad de Parkinson ambulatorios y sus factores de riesgo. Rev Méd Chile 141: 320-326.

2. Beitz JM (2014) Parkinson's disease: a review. Front Biosci (Schol Ed) 1: 65-74.

3. Yarnall A, Archibald N, Burn D (2012) Parkinson's disease. Medicine 40: 529-535.

4. Zaragoza Salcedo A, Senosiain García JM, Riverol Fernández M, Anaut Bravo S, De Cerio Ayesa SD, et al. (2014) Key elements in the process of 
Citation: Nunesc SFL (2017) Indicators of the Process of Transition to the Exercise of Family Caregivers of Elderly with Parkinson's Disease: A Qualitative Study. J Nurs Care 6: 430. doi:10.4172/2167-1168.1000430

Page 7 of 7

living with Parkinson's disease for patients and caregivers. Anales Sis San Navarra 37: 69-80.

5. Pinto JMS, Nations MK (2012) Care and chronic illness: Family caregiver's viewpoint in north-east Brazil. Cienc Saúde colet 17: 521-530.

6. García-Ramos R, López Valdés E, Ballesteros L, Jesús S, Mir P (2013) The social impact of Parkinson's disease in Spain: Report by the Spanish Foundation for the Brain. Neurología 28: 1-13.

7. Abendroth M, Lutz BJ, Young ML (2012) Family caregivers' decision process to institutionalize persons with Parkinson's disease: A grounded theory study. Int J Nurs Stud 49: 445-454.

8. Navarro-Peternella FM, Marcon SS (2012) Quality of life of a person with Parkinson's disease and the relationship between the time of evolution and the severity of the disease. Rev Latino-Am Enfermagem 20: 384-391.

9. Meleis AI, Sawyer LM, Im EO, Hilfinger Messias DK, Schumacher K (2000) Experiencing transitions: An emerging middle-range theory. ANS Adv Nurs Sci 23: 12-28

10. Chick N, Meleis AI (2010) Transitions: A nursing concern, In: Meleis, AI. Transitions theory: Middle range and situation-specific theories in research and nursing practice. Springer Publishing Company, New York.

11. Kerouac S, Pepin J, Ducharme F, Duquette A, Major F (2010) Nursing thinking. Barcelona.

12. Meleis AI, Trangenstein PA (2010) Facilitating transitions: Redefinition of a nursing mission. Nursing Outlook In: Meleis A. Transitions Theory: Middle range and situation-specific theories in research and nursing practice. Springer Publishing Company, New York.

13. Meleis AI (2010) Transitions theory: Middle range and situation-specific theories in research and nursing practice. Springer Publishing Company, New York.

14. Fontanella BJB, Magdaleno RJ (2012) Theoretical saturation in qualitative research: psychoanalytical contributions. Psicol Estud 17: 63-71.

15. Bardin L (2011) Content analysis. Editions, São Paulo.

16. Oliveira SG, Kruse MHL, Sartor SF, Echevarría-Guanilo ME (2015) Enunciados sobre a atenção domiciliar no cenário mundial: revisão narrativa. Glob Nurs 39: 375-389.
17. Ducharme FC, Lévesque LL, Lachance LM, Kergoat MJ, Legault AJ, et al. (2011) Learning to become a family caregiver: Efficacy of an intervention program for caregivers following diagnosis of dementia in a relative. The Gerontologist 51: 484-494.

18. Kristjanson LJ, Aoun SM, Oldham L (2006) Palliative care and support for people with neurodegenerative conditions and their carers. Int J Palliat Nurs 12: 368-77.

19. Landeiro MJL, Peres HHC, Martins T (2015) Avaliação de necessidades informacionais dos cuidadores domiciliares. Rev Enferm UFSM 5: 486-498.

20. Gonçalves LHT, Alvarez AM, Arruda MC (2007) Patients' experience with Parkinson's disease. Acta Paul Enferm 20: 62-68.

21. Hellqvist C, Berterö C (2015) Support supplied by Parkinson's disease specialist nurses to Parkinson's disease patients and their spouses. Appl Nurs Res 28: 86-91.

22. Beaudet L, Ducharme F (2013) Living with moderate-stage Parkinson disease: Intervention needs and preferences of elderly couples. J Neurosci Nurs 45: 88-95.

23. Sanyal J, Das S, Ghosh E, Banerjee TK, Bhaskar LV, Rao VR (2015) Burden among Parkinson's disease care givers for a community based study from India. J Neurol Sci 355: 276-281.

24. Carvalho DP, Toso BRGO, Viera CS, Garanhani ML, Rodrigues RM, et al. (2015) Caregivers and implications for home care. Texto contexto enferm 24: 450-458.

25. Davies S (2005) Meleis's theory of nursing transitions and relatives' experiences of nursing home entry. J Adv Nurs 52: 658-671.

26. Gwyn MV (2009) Parkinson disease and the nurse practitioner: Diagnostic and management challenges. J Nurs Pract 5: 195-206.

27. Petronilho FAS, Pereira FMS, Silva AAP (2015) Perception of self-efficacy of family caregivers after the dependent homecoming: A longitudinal study. Portuguese J Ment Health Nurs09-13. 